\title{
Construction and analysis of a subtractive cDNA library of early embryonic development in duck
}

\author{
Y.L. Liu', ${ }^{1,2}$, L.X. Zhong', ${ }^{1,2}$ J.J. Li' ${ }^{2}$,J.D. Shen ${ }^{2}$, D.Q. Wang ${ }^{2}$, Z.R. Tao ${ }^{2}$, \\ F.X. Shi ${ }^{1}$ and L.Z. Lu $^{2}$ \\ ${ }^{1}$ College of Animal Science and Technology, Nanjing Agricultural University, \\ Nanjing, China \\ ${ }^{2}$ Institute of Animal Husbandry and Veterinary Science, \\ Zhejiang Academy of Agricultural Sciences, Hangzhou, China
}

Corresponding author: F.X. Shi

E-mail: fxshi@njau.edu.cn

Genet. Mol. Res. 12 (3): 2234-2247 (2013)

Received August 8, 2012

Accepted March 20, 2013

Published July 8, 2013

DOI http://dx.doi.org/10.4238/2013.July.8.5

\begin{abstract}
Several studies have documented the process of early embryonic development in poultry; however, the molecular mechanisms underlying its developmental regulation are poorly understood, particularly in ducks. In this study, we analyzed differential gene expression of embryos 6 and $25 \mathrm{~h}$ following oviposition to determine which genes regulate the early developmental stage in ducks. Among 216 randomly selected clones, 39 protein-encoding cDNAs that function in metabolism, transcription, transportation, proliferation/apoptosis, cell cycle, cell adhesion, and methylation were identified. Additionally, the full-length cDNA of the Nanog gene, encoding a 302-amino acid protein, was obtained. Quantitative real-time polymerase chain reaction analyses were performed to detect expression levels of the selected genes during early and late embryonic stages, which revealed that these genes are expressed in a particular spatial and temporal pattern. These results indicate that these genes may play pivotal roles in the process
\end{abstract}


of area pellucida formation through a complex and precise regulatory network during development in duck embryos.

Key words: Duck; Embryo development; Subtractive hybridization; Duplex-specific nuclease; Nanog

\section{INTRODUCTION}

Early embryonic mortality is a major problem plaguing the poultry industry (Coleman, 1983; Dupuy, 2002), but its biological basis remains unknown. The normal embryonic developmental sequence in poultry, including ducks, is established by specific stages of morphogenetic progression during the preoviposition and incubation periods (Eyal-Giladi and Kochav, 1976; Gupta and Bakst, 1993; Bakst et al., 1997; Sellier et al., 2006). Yet, the molecular regulation of early embryonic development remains unclear, particularly in ducks.

Eyal-Giladi and Kochav (1976) developed a 14-stage classification (EGK stages) according to morphogenetic development in the early chicken embryo during the oviductal period. Similar staging procedures have been described for turkey (Gupta and Bakst, 1993) and Pekin duck (Dupuy et al., 2002). Development in the Pekin duck embryo is divided into a cleavage phase, in which cell division occurs regularly (stages EGK I-VI), and the area pellucida formation phase, during which thinning in the central zone of the blastoderm occurs as a consequence of cell shedding (EGK stages VII-IX). Although the relative rates of embryonic development differ among species and strains, the stage of embryonic development can be identified by nearly identical external features. Therefore, in this study, following the standards of Eyal-Giladi and Kochav (1976) and Dupuy et al. (2002) study of temporal development in poultry, each stage of duck development was characterized based on morphological criteria.

The aims of this study were to identify known and novel candidate genes playing potential roles in the regulation of morphogenetic changes and area pellucida formation in the duck blastoderm, and to identify the expression profile of certain genes in early and late embryo stages. In ducks, the egg enters the uterus with a translucent or opaque shell membrane $6 \pm 1 \mathrm{~h}$ following oviposition (EGK stages II-III) when the embryo is in the early cleavage period, which is characterized by several closed cells in its center. At $20 \pm 1 \mathrm{~h}$ after oviposition (EGK stages VI-VII), the egg mass has been in the uterus for $13-15 \mathrm{~h}$ and is surrounded by a hard shell. At this stage, the embryo is referred to as a blastoderm, and shed cells from its ventral surface at the posterior end of the embryo, and the area pellucida begins to develop. When the egg is freshly laid (within $1 \mathrm{~h}$ of oviposition) with a complete shell (EGK stages VIII-IX), the extension of the area pellucida toward the anterior part can be observed, and the boundary between the area pellucida and the area opaca becomes more distinct. This stage is called the area pellucida formation period, which is not only the end of blastoderm development in vivo, but also the beginning of hypoblast formation.

To investigate the molecular mechanisms that regulate early embryonic development and identify related functional genes in ducks, the blastodiscs of fertilized eggs were isolated from the oviduct and at oviposition, and differentially expressed genes were identified by a novel subtractive hybridization method called duplex-specific nuclease (DSN)-mediated normalization and subtractive hybridization (DNSH) (Ji et al., 2002; Dai et al., 2009). Many genes, including several known self-renewal and pluripotency-specific genes, such as Nanog, 
DNA (cytosine-5-)-methyltransferase 3 beta (DNMT3B), heat shock protein-90 (HSP90), and $D E K$, are differentially expressed between the early cleavage and the area pellucida formation periods. $H S P 90$ and $D E K$ expression levels were examined at a later developmental stage. The results suggest that morphological development in early duck embryos is accompanied by expression of specific transcription factors that dictate the overall plan of the early embryo and may play a role in special tissue development.

\section{MATERIAL AND METHODS}

\section{Egg selection}

We selected 60 fertilized female ducks (high yield period) with similar genetic backgrounds. The daily egg times of the ducks were observed and recorded for 30 days, and then the ducks were euthanized by cervical dislocation 6,20 , and $25 \mathrm{~h}$ after oviposition ( \pm $1 \mathrm{~h}$ ), and the oviduct egg mass was removed before it was completely molded. In addition, embryos from freshly laid eggs (removed within $1 \mathrm{~h}$ of oviposition) were also evaluated. Approximately 20 embryos were assessed per time period. We also isolated tissue from fertilized eggs at days 15, 21, and 27 during incubation, and from 4 euthanized embryos at each developmental stage.

\section{Blastoderm preparation}

Eggshells were opened and placed on Petri dishes. The yolk was gently turned upside down in order to view the blastoderm, which was then grasped and detached with fine forceps. Ten blastoderm pieces (6 and $20 \mathrm{~h}$ after oviposition and from freshly laid eggs), and all tissues (brain, heart, and liver, obtained 15, 21, and 27 days after incubation, respectively) were frozen immediately in liquid nitrogen and stored at $-80^{\circ} \mathrm{C}$ for RNA extraction.

\section{RNA isolation and cDNA synthesis}

Total RNA was isolated from the blastoderm and from the brain, heart, and liver using the AxyPrep Multisource Total RNA Miniprep Kit (Axygen, San Francisco, CA, USA) and an RNA Prep Pure Tissue Kit (Tiangen, Beijing, China), following manufacturer protocols. The concentration and purity of total RNA was determined with a spectrophotometer (NanoVue, GE Healthcare, Piscataway, NJ, USA), and integrity was examined on $1.2 \%$ agarose gels containing $0.1 \%$ ethidium bromide. First-strand cDNA was synthesized from $1 \mu \mathrm{g}$ total RNA in each sample using the TransScript First-Strand cDNA Synthesis SuperMix (TransGen Biotech, Beijing, China) for use in quantitative reverse transcription-polymerase chain reaction (RT-PCR) analyses.

\section{Construction of normalized and subtracted cDNA libraries}

cDNA libraries were constructed with DNSH according to previously established methods (Ji et al., 2002; Dai et al., 2009). The main procedure was as follows. First, the firststrand and double-stranded cDNA were synthesized by PCR. The PCR products were purified 
using the QIA Quick PCR Purification Kit (Qiagen, Valencia, CA, USA). The RNA of the test group was again reverse transcribed with the T7oligo-dT primer to generate the tester RNA. Second, tester cDNA and excess driver RNA were hybridized, following an addition of the DSN to specifically cleave DNA into DNA:DNA or DNA:RNA forms. Finally, the subtracted cDNAs were amplified with 3 rounds of PCR using different primers. PCR products with fragment lengths $>500$ bp were purified using the QIA Quick Gel Extraction Kit (Qiagen), ligated with the pUCmT vector, transformed, and plated. In total, 216 white recombinant colonies were randomly selected. After being shaken overnight, the cDNA of fragments $>750 \mathrm{bp}$ were sequenced using the M13F and M13R vector primers (Table 1).

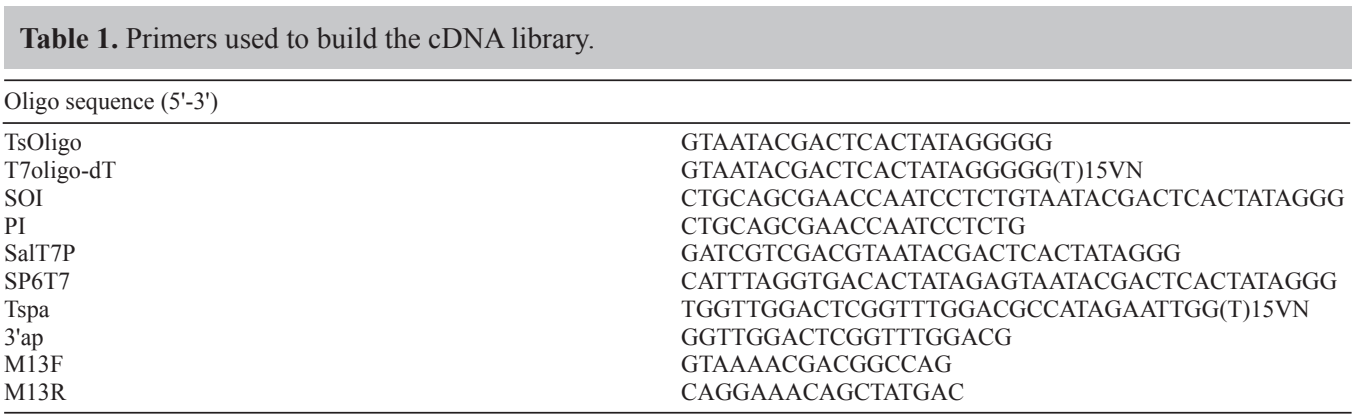

\section{Sequence analysis of differentially expressed genes}

After the vector and redundant sequences were removed using Vecscreen (http:// www.ncbi.nlm.nih.gov/VecScreen/VecScreen.html) and the Staden Package, respectively, a sequence homology search was performed against GenBank databases using BLASTX and BLASTN (http://www.ncbi.nlm.nih.gov/BLAST) to achieve gene annotation (Table 2). The differentially expressed genes identified were categorized using Gene Ontology (http://www. geneontology.org/).

\section{Quantitative RT-PCR validation}

Real-time RT-PCR was used to validate the differential expression patterns of 6 selected genes. Gene-specific primers (Table 3) were designed with the Primer 5.0 software. $18 S$ rRNA and $\beta$-actin were used as reference genes for the blastoderm and embryonic tissues, respectively, including the heart, liver, and brain. RT-PCR was run in triplicate using an ABI 7300 instrument (Applied Biosystems, Foster City, CA, USA) at $94^{\circ} \mathrm{C}$ for $3 \mathrm{~min}$, $94^{\circ} \mathrm{C}$ for $10 \mathrm{~s}$, and 40 cycles at $60^{\circ} \mathrm{C}$ for $30 \mathrm{~s}$. RT-PCR was performed in a $25-\mu \mathrm{L}$ reaction mixture, containing $1 \mu \mathrm{L}$ cDNA template, $1 \mathrm{X}$ THUNDERBIRD SYBR qPCR Mix, 1X ROX reference dye (TOYOBO, Tokyo, Japan), and $0.4 \mu \mathrm{M}$ each primer. The relative expression levels of the genes tested were calculated using the $2^{-\Delta \mathrm{Ct}}$ method $(\Delta \mathrm{Ct}=$ cycle threshold $(\mathrm{Ct})$ of the target gene - Ct of $18 S \mathrm{rRNA} / \beta$-actin). Data are reported as means $\pm \mathrm{SE}$. Differences between groups were examined with the Student $t$-test and were considered to be significant when $\mathrm{P}<0.05$. 


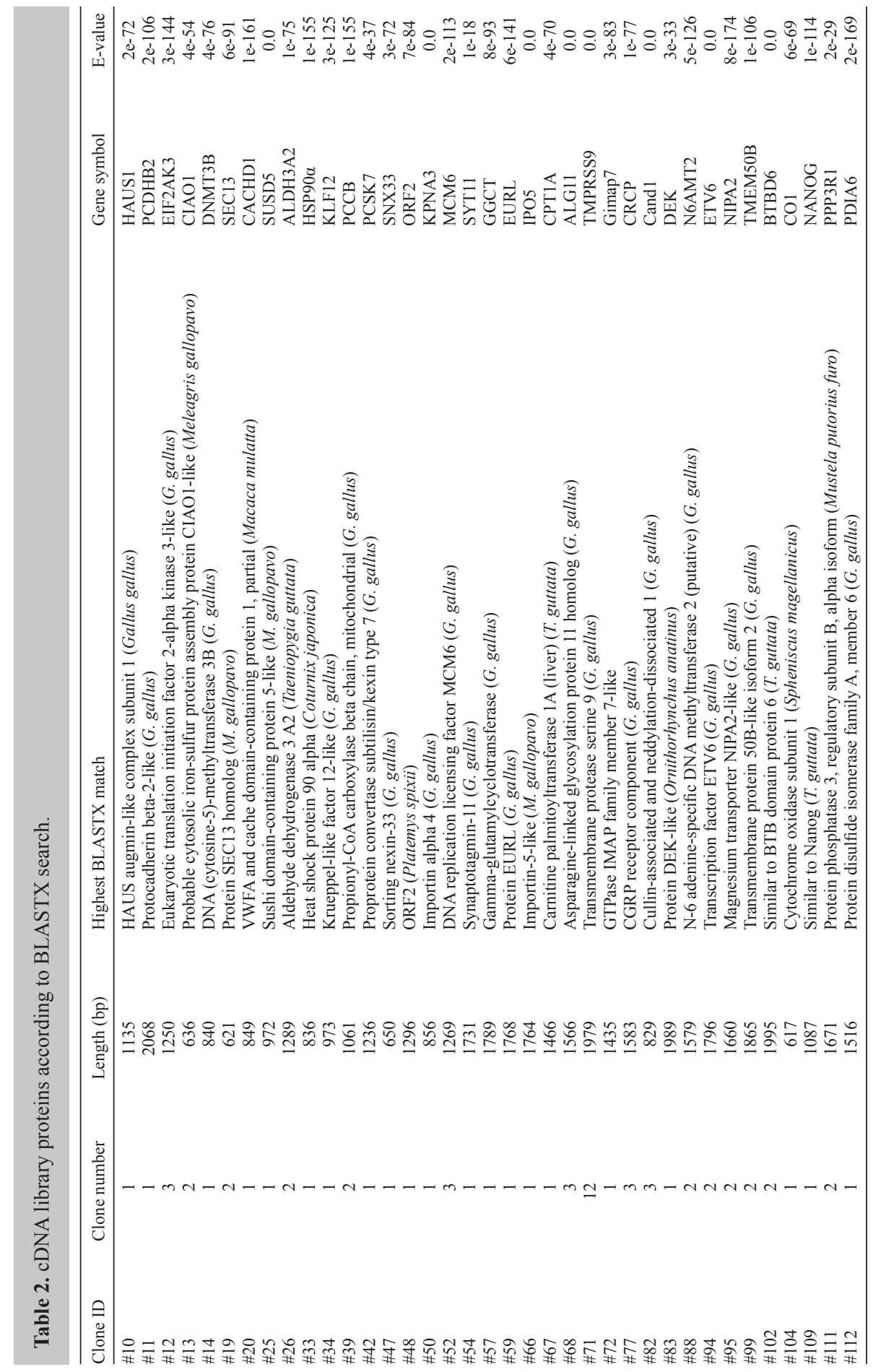


Table 3. Primers used for the RT-PCR analysis.

\begin{tabular}{lclc}
\hline Primer & Binding sites & Nucleotide sequences (forward and reverse) $\left(5^{\prime} \rightarrow 3^{\prime}\right)$ & Gene size $(\mathrm{bp})$ \\
\hline NanogF & $392-410$ & CCACAACCTACTGCTAAGCC & 1087 \\
NanogR & $598-580$ & TCTGGAACCAAGTCTTCACC & 841 \\
DNMT3BF & $288-269$ & TCCACTACACCGACGTTTCCA & 836 \\
DNMT3BR & $405-387$ & GACGCTCCGCTTGCTATTCA & \\
HSP90AA1F & $400-381$ & GTGGATACAGGCATAGGGAT & 1989 \\
HSP90AA1R & $558-539$ & AACAAGGTAGGCGGAGTAGA & 1583 \\
DEKF & $280-260$ & CAAATTTGCAAGGAGGTGTAC & 1250 \\
DEKR & $447-428$ & GGTGCCTATCAGATCTTCAA & \\
CRCPF & $777-758$ & CCATTACCCATGT AACAGCTG & 862 \\
CRCPR & $952-932$ & CGTATCGATCCCTGAAAATAGC & \\
EIF2AK3F & $518-499$ & TTTCCACCGCTGTTCATTCA & \\
EIF2AK3R & $686-667$ & TTGTCCGTGACCTCTGCCTA & \\
RS18F & $206-184$ & CAACTTTCGATGGTAGTGTCTGTG & \\
RS18R & $304-286$ & TGGATGTGGTAGCCGTTTCT & \\
\hline
\end{tabular}

\section{RESULTS}

\section{Results of the DNSH process}

The result of each step of the DNSH method is shown in Figure 1A-E. The integrity of total RNA was assessed to visualize the 28S and 18S RNA (Figure 1A). Two groups were evident in the coating strip shape, and the cDNA insert size was 0.5-3 kb (Figure 1B). PCR amplification of the subtractive product was optimal after 20 cycles (Figure 1C). A clear band was concentrated at approximately $1.8 \mathrm{~kb}$ after the subtracted cDNAs were amplified by 3 rounds of PCR (Figure 1D). The results of 216 positive clones were tested by PCR amplification (Figure 1E).

\section{Analysis of differentially expressed genes}

We acquired 66 differently expressed sequences among the clones, and 35 proteincoding cDNAs were identified using BLASTN and BLASTX searches. The sequences were categorized into 8 functional groups, including metabolism (21.05\%), transcription (15.79\%), transport $(18.42 \%)$, proliferation/apoptosis $(13.16 \%)$, cell cycle $(7.89 \%)$, cell adhesion (5.26\%), methylation (5.26\%), and unknown function (13.16\%) (Figure 2). Most of these proteins appeared to be associated with metabolism, such as that of fatty acids and glycerol or transcription.

\section{Analysis of the Nanog sequence}

We isolated full-length cDNA of Nanog (GenBank accession No. HQ699480) with an open reading frame of 909 bp encoding a 303-amino acid (aa) protein, using the DNSH method. The complete protein and homeodomain sequence of this gene was compared with that of the zebra finch, chicken, mouse, and human (Figure 3). A homeodomain of 63 aa, located between aa 109 and 171, was predicted in the duck Nanog protein using InterProScan (http://www.ebi.ac.uk/Tools/pfa/iprscan/) (Table 4). 
A

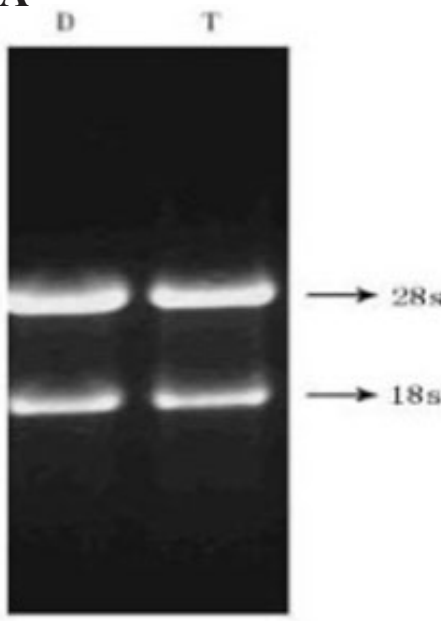

B

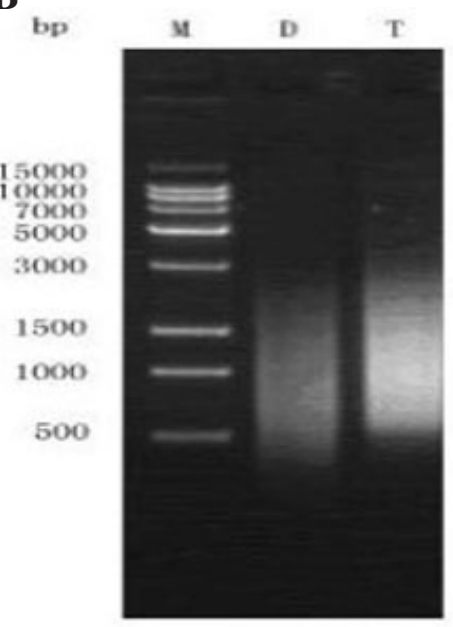

C

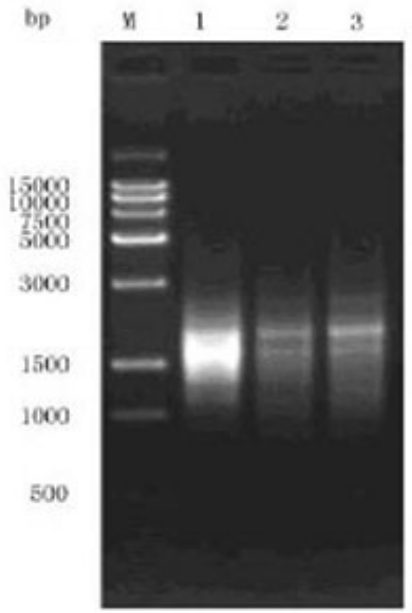

D

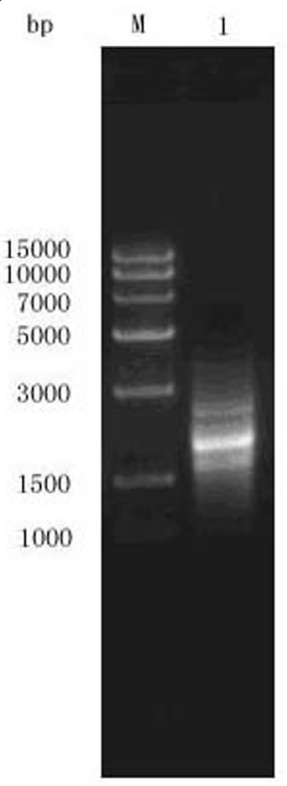

$\mathbf{E}$

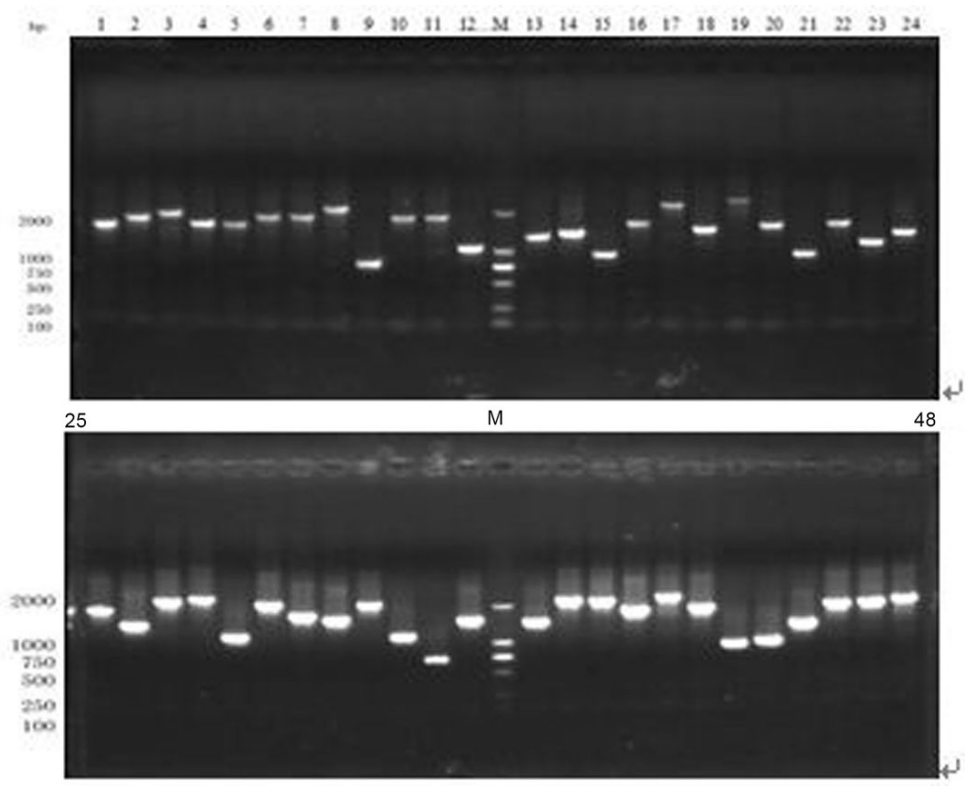

Figure 1. Intermediate steps of the duplex-specific nuclease (DSN)-mediated subtractive hybridization. A. Total RNA run on an agarose gel showing prominent 28S and 18S RNA bands. D and T represent driver and tester groups from 6 and $25 \mathrm{~h}$ after the previous oviposition, respectively. B. Two groups existed in the coating strip shape, and cDNA insert size was $0.5-3 \mathrm{~kb}$. C. The subtractive product was amplified 20, 25 , and 30 cycles to determine the best suitable condition (20 cycles). Lanes 1, 2, and $3=20,25$, and 30 cycles, respectively. D. After the subtracted cDNAs were amplified by 3 rounds of PCR, a clear band was concentrated at $1.8 \mathrm{~kb}$. Lane $M=$ molecular marker; lane $1=\mathrm{cDNAs}$ E. Part of the positive clones (lanes $1-48$ ) tested by PCR amplification of bacterium fluid with $\mathrm{M} 13 \mathrm{~F} / \mathrm{R}$ as primers. Lane $M=$ molecular marker; lanes $1-48=$ PCR products. 


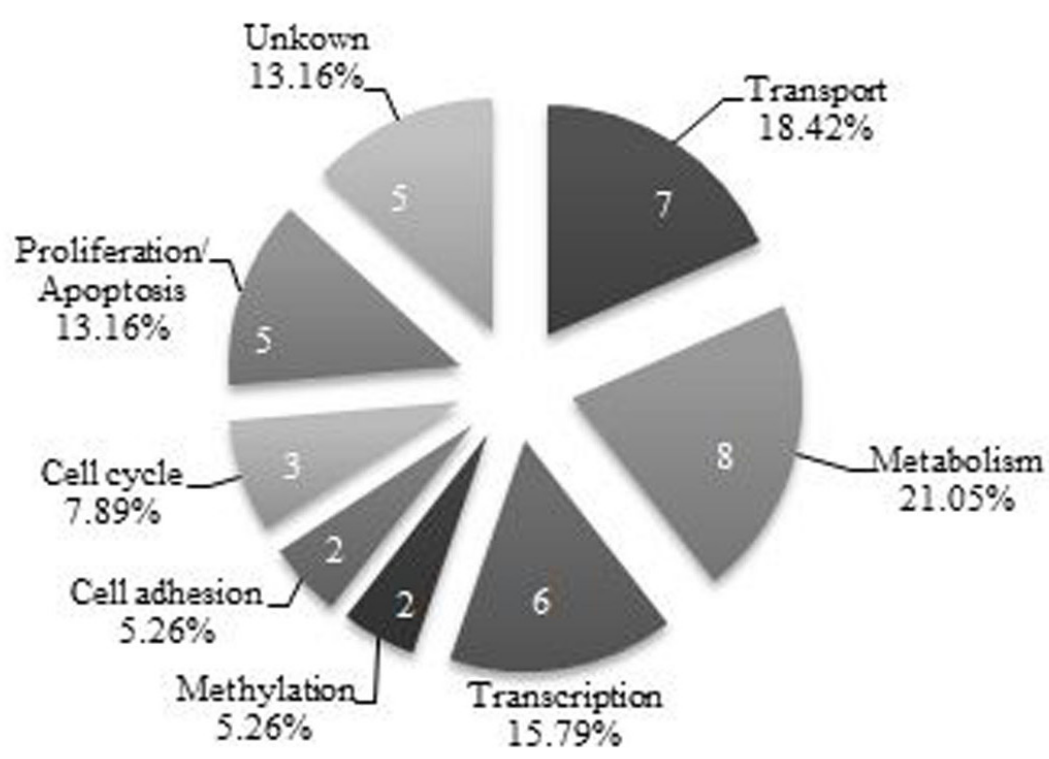

Figure 2. Functional classification of the genes isolated from this screen according to the biological process described at http://www.geneontology.org/.

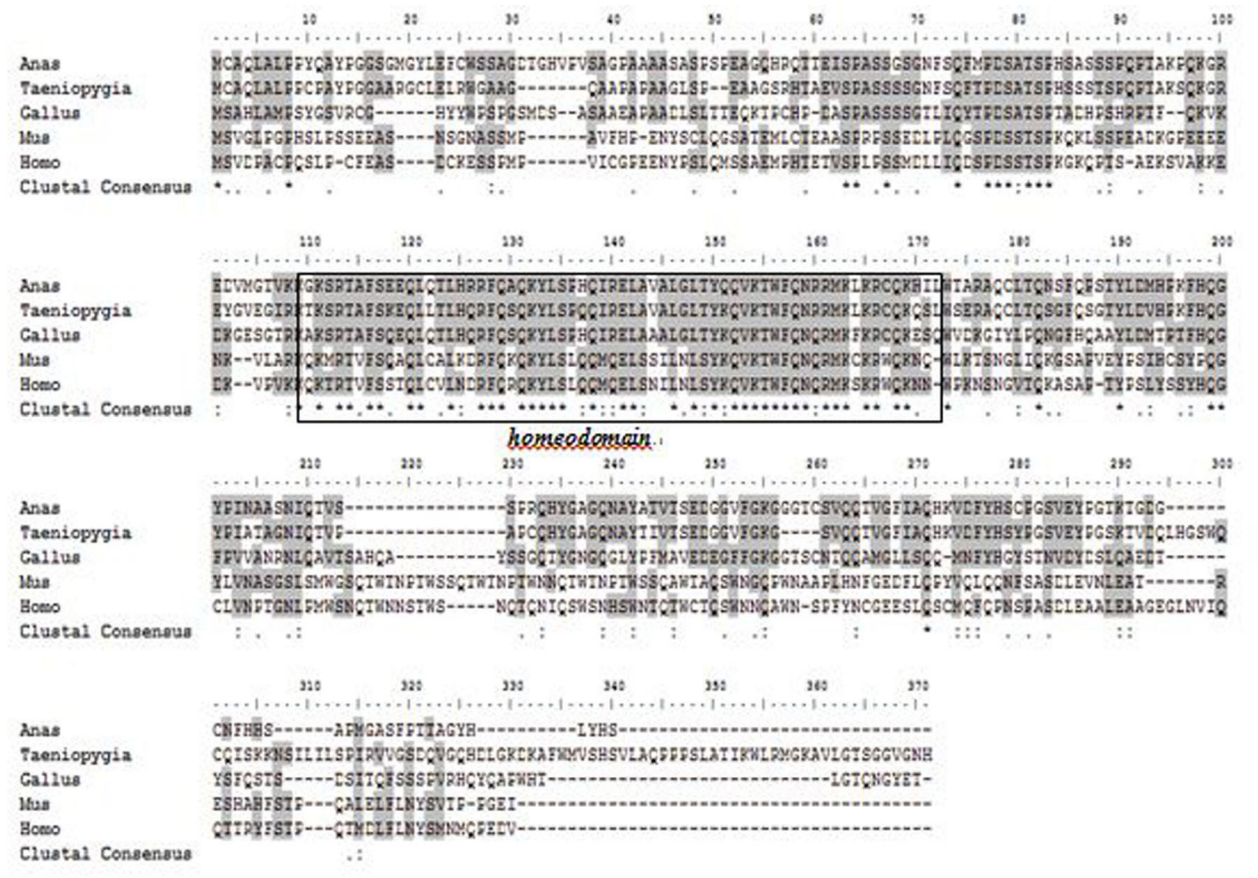

Figure 3. Alignment of the deduced amino acid sequences of Nanog in Anas platyrhynchos (JX069972), Taeniopygia guttata (XP_002190766), Gallus gallus (NP_001139614), Homo sapiens (NP_079141), and Mus musculus (NP_082292) using the ClustalX software. The special homeodomains are indicated in the rectangular box. 
Table 4. Similarity analysis of the Nanog coding full-length proteins and homeodomains in the five species.

\begin{tabular}{|c|c|c|c|c|c|c|c|c|c|c|c|c|c|c|}
\hline \multirow[t]{2}{*}{ Species } & \multirow[t]{2}{*}{ GenBank No. } & \multirow[t]{2}{*}{ Ap } & \multirow[t]{2}{*}{$\mathrm{Tg}$} & \multirow[t]{2}{*}{$\mathrm{Gg}$} & \multirow[t]{2}{*}{ Hs } & \multirow[t]{2}{*}{$\mathrm{Mm}$} & \multicolumn{3}{|c|}{ Homeodomain } & \multirow[t]{2}{*}{ Ap } & \multirow[t]{2}{*}{$\mathrm{Tg}$} & \multirow[t]{2}{*}{$\mathrm{Gg}$} & \multirow[t]{2}{*}{ Hs } & \multirow[t]{2}{*}{$\mathrm{Mm}$} \\
\hline & & & & & & & Start & End & Size & & & & & \\
\hline Anas platyrhynchos & JX069972 & 100 & 71 & 49 & 40 & 45 & 109 & 171 & 63 & 100 & 87 & 87 & 61 & 61 \\
\hline Taeniopygia guttata & XP 002190766 & & 100 & 49 & 40 & 43 & 100 & 162 & 63 & & 100 & 87 & 63 & 66 \\
\hline Gallus gallus & NP 001139614 & & & 100 & 46 & 45 & 98 & 160 & 63 & & & 100 & 63 & 66 \\
\hline Homo sapiens & NP 079141 & & & & 100 & 58 & 95 & 157 & 63 & & & & 100 & 87 \\
\hline Mus musculus & NP_082292 & & & & & 100 & 96 & 158 & 63 & & & & & 100 \\
\hline
\end{tabular}

$\mathrm{Ap}=$ A. platyrhynchos $; \mathrm{Tg}=$ T. guttata $; \mathrm{Gg}=$ G. gallus $; \mathrm{Hs}=H$. sapiens; $\mathrm{Mm}=$ M. musculus.

\section{Expression patterns of selected cDNA clones by RT-PCR}

The genes analyzed were differentially expressed during the time course of development. Expression levels of Nanog and HSP90 $\alpha$ were both highly upregulated compared to the other genes analyzed. Nanog mRNA was not detected $6 \mathrm{~h}$ after oviposition, whereas both Nanog and HSP90 $\alpha$ were detected at 20 and $25 \mathrm{~h}$ after oviposition, although expression of $H S P 90 \alpha$ was significantly higher compared to that of $\operatorname{Nanog}(\mathrm{P}<0.05)$. The expression levels of DNMT3B, HSP90 $\alpha$, and DEK mRNA increased gradually during embryonic development $(\mathrm{P}<0.05)$ (Figure 4).

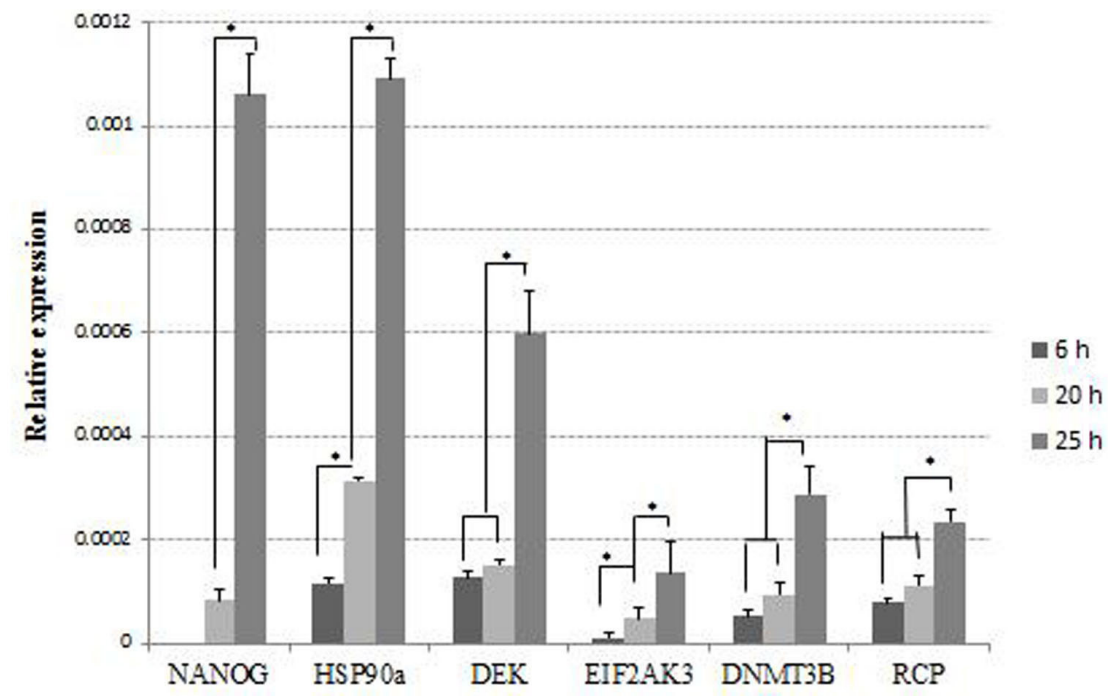

Figure 4. Expression levels of the selected genes determined by quantitative RT-PCR and normalized to that of $18 \mathrm{~S}$ rRNA. Each column represents the mean of gene expression \pm standard error in five blastoderms 6, 20, and $25 \mathrm{~h}$ after the previous oviposition. *Significant difference at $\mathrm{P}<0.05$.

\section{$H S P 90 \alpha$ and $D E K$ expression patterns during the late stage of embryonic development}

Nanog mRNA was not detected, and the expression level of DNMT3B was lower in the heart, liver, and brain during incubation at days 15,21, and 27. HSP90 $\alpha$ and DEK mRNA expression levels increased gradually during development in the heart, brain, and liver, and were significantly higher $(\mathrm{P}<0.05)$ in the brain and heart (Figure 5). 
A

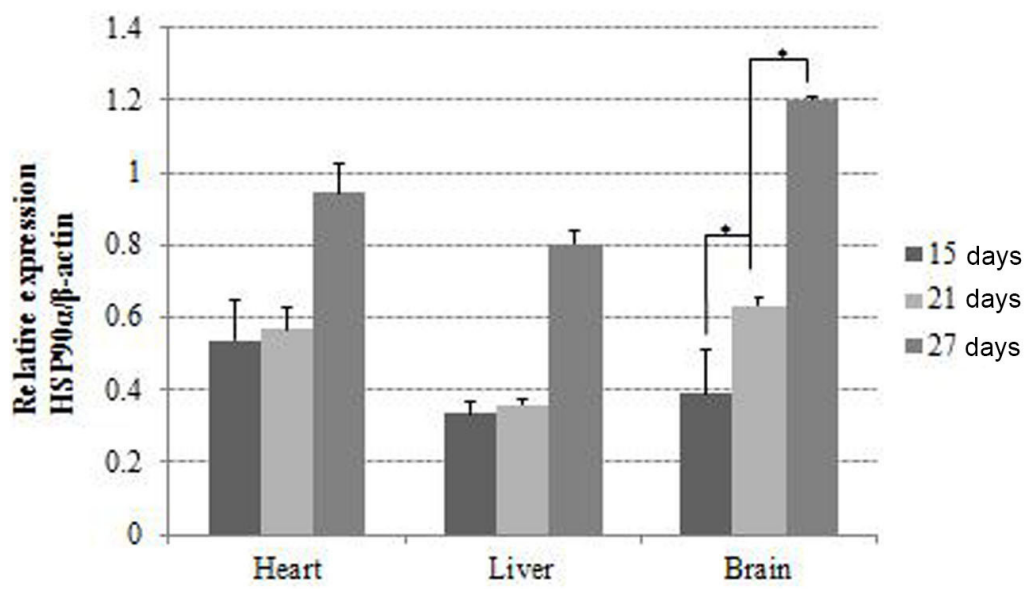

B

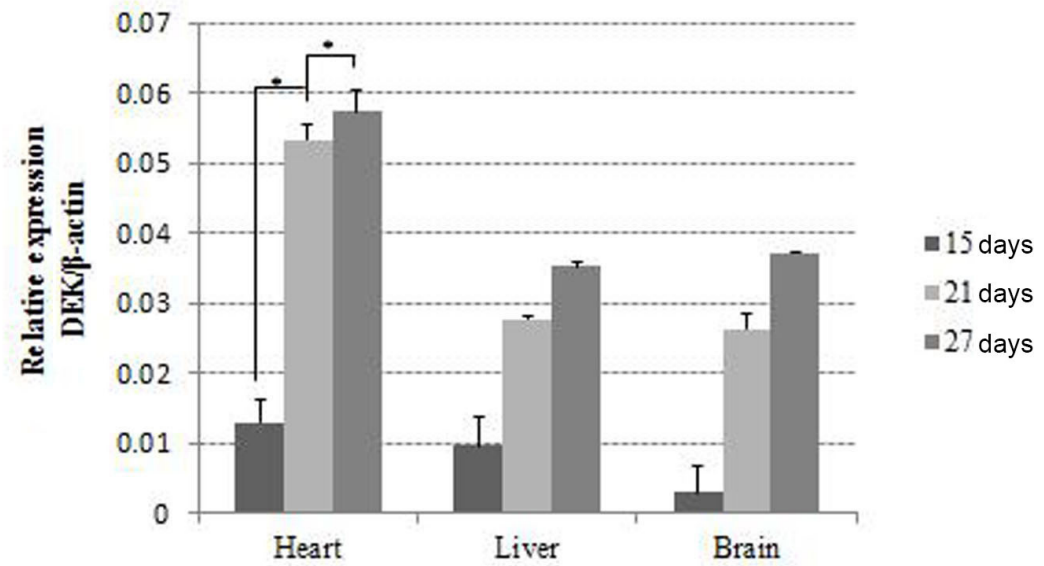

Figure 5. Expression levels of the heat shock protein-90 $\alpha(\mathrm{HSP} 90 \alpha)(\mathbf{A})$ and DEK (B) mRNA determined by quantitative RT-PCR and normalized to that of $\beta$-actin. Each column represents the mean of 4 individual ducks \pm standard error at days 15,21 , and 27 during incubation. * Significant difference at $\mathrm{P}<0.05$.

\section{DISCUSSION}

Early embryonic development has been directly associated with hatching rate in the duck industry. Dupuy et al. (2002) described progressive developmental stages according to the morphogenetic development of the early duck embryo during the oviductal period. However, few studies have examined the molecular mechanisms underlying early embryonic development in ducks. Thus, we used a DNSH screen to identify genes with different expression patterns in 6-25 h blastoderms, as some of the genes were predicted to be involved in the regulation of early embryonic development.

DNSH is a recently established method based on classic suppression subtractive hybridization (Diatchenko et al., 1996), DSN-mediated transcriptome subtraction (Peng et 
al., 2008), and full-length normalization subtractive hybridization methods (Ji et al., 2002). DSN shows maximal activity at $65^{\circ} \mathrm{C}$ and specifically cleaves DNA into DNA:DNA or DNA:RNA forms (Zhulidov et al., 2004; Anisimova et al., 2008). However, some cDNA fragments broke as a result of the experimental procedure. We isolated full-length cDNA of Nanog, with an open reading frame of 909 bp encoding a 303-aa protein, which did not have a 10-pentapeptide repeat at the C-terminus; a prominent feature of the mammalian Nanog subfamily (Pan and Pei., 2005). This sequence was similar to those of the chicken and the axolotl (Lavial et al., 2007).

Nanog is a critical regulator of self-renewal and pluripotency in embryonic stem cells and prevents differentiation into the primitive endoderm during embryonic development. Nanog was first identified and named by two independent groups using different strategies (Chambers et al., 2003; Mitsui et al., 2003). These researchers first detected Nanog mRNA in morulae, rather than during early cleavage, up to the early blastocyst stage, and then found that it was restricted to the inner cell mass during mouse embryo development (Hart et al., 2004; Hatano et al., 2005). These results are consistent with the expression pattern of Nanog in ducks and indicate that its regulatory mechanisms during early development may not be exclusive to mammals.

De novo methylation is crucial for normal embryonic development, such as genomic imprinting (Hore et al., 2007) and gene silencing (Lande-Diner et al., 2007; Miranda and Jones, 2007). Abnormal patterns of DNA methylation result in early embryonic lethality in mice (Li et al., 1992; Okano et al., 1999). De novo methylation is carried out through two methyltransferases, DNMT3A and DNMT3B. DNMT3B is specifically expressed in E4.5 7.5 mouse embryos and is very low expressed after differentiation (Watanabe et al., 2002). This pattern is similar to the expression profile of $D N M T 3 B$ observed in ducks.

Notably, the role of de novo methylation in regulating Nanog expression during embryonic stem cell self-renewal and differentiation has been under intense investigation (Deb-Rinker et al., 2005; Li et al., 2007; Fouse et al., 2008). These studies validated that, at least in part, DNMT3A and DNMT3B cooperate in the methylation of Nanog and Oct4 promoters during cell differentiation. When the duck egg is freshly laid $(25 \mathrm{~h}$ after oviposition), the embryo grows to the late blastocyst stage and is about to begin differentiation to the hypoblast stage. The Nanog promoter, or its target gene, may be methylated, which leads to downregulation, and the hypoblast begins to differentiate as a result of the upregulation of $D N M T 3 B$. However, this hypothesis needs further validation.

As a dimmer, HSP90 can influence development, epigenetic changes, and morphological evolution (Pearl et al., 2008). mRNA expression of the HSP90 $\alpha$ isoform increases at the G1/S transition in chicken hepatoma cells (Jérôme et al., 1993). In addition, depletion of $H S P 90 \alpha$ leads to failure of proper somite and muscle development and paralyzes zebrafish embryos (Lele et al., 1999; Etard et al., 2007, 2008). HSP90 $\alpha$ and $H S P 90 \beta$ are expressed at the 8-cell cleavage and blastocyst stages during early embryonic development (Mezger et al., 1991), which is consistent with our results.

The DEK protein was originally identified as a fusion protein in a subset of patients with acute myeloid leukemia (von Lindern et al., 1992). Differentiation results in $D E K$ downregulation in human promyelocytic HL-60 cells and in human foreskin keratinocytes, and in turn, overexpression of $D E K$ counteracts cell differentiation (Savli et al., 2002; Wise-Draper et al., 2009b) and promotes proliferation and transformation of epithelial cells 
(Wise-Draper et al., 2009a). The $D E K$ gene was originally described during early embryonic development, but is preferentially expressed in actively proliferating cells and can inhibit cell differentiation, senescence, and apoptosis. Thus, identifying DEK in 25-h blastoderms by the suppression subtractive hybridization method is not unexpected. This result shows that DEK is not only very important in carcinogenesis, but is also important in early embryogenesis, as it is involved in the decision to proliferate or differentiate.

Nanog mRNA was not detected and DNMT3B mRNA was expressed at a low level in the heart, liver, and brain during incubation for 15, 21, and 27 days, respectively. This result was consistent with several previous experiments. The expression patterns of $H S P 90 \alpha$ and $D E K$ indicate that they may also play an important role during the late stages of embryonic development, particularly in the formation of brain and heart tissues. However, additional studies are required to clarify the mechanisms regulating brain and heart development.

Proper early embryonic development depends on a delicate balance among cell proliferation, differentiation, and apoptosis, which is regulated by key genes in a well-defined modulation network. Note that Nanog, HSP90, and DEK all have direct or indirect relationships with $\mathrm{p} 53$, which transactivates pro-apoptotic genes and begins differentiation during embryonic development. Many investigators have demonstrated that loss of p53 function promotes stemness and self-renewal, whereas active p53 suppresses Nanog function. p53 binds to the Nanog promoter in vitro and in vivo (Lin et al., 2005). Some studies have shown that the role of DEK in cellular survival is realized by destabilizing p53-mediated apoptosis, implicating $p 53$ as a DEK target gene (Wise-Draper et al., 2006). HSP90 stabilizes the conformations of mutant proteins, including v-src, Bcr-Abl, and p53 (Neckers, 2002). Therefore, early embryonic development is finely regulated by a complex network of cell proliferation and differentiation transcription factors whose genes are silent or active. However, further studies are required to clarify the functional mechanisms of these key genes in ducks, as they will provide a better understanding of the regulatory mechanism underlying early embryonic development, and provide basic data for improving the hatchability rate of fertile eggs for the duck industry.

\section{ACKNOWLEDGMENTS}

Research supported by the International Cooperation Project of Zhejiang Province of China (\#2008C14073), and an Earmarked Fund for the Modern Agro-Industry Technology Research System (\#CARS-43-02A).

\section{REFERENCES}

Anisimova VE, Rebrikov DV, Shagin DA, Kozhemyako VB, et al. (2008). Isolation, characterization and molecular cloning of duplex-specific nuclease from the hepatopancreas of the Kamchatka crab. BMC Biochem. 9: 14.

Bakst MR, Gupta SK and Akuffo V (1997). Comparative development of the turkey and chicken embryo from cleavage through hypoblast formation. Poult. Sci. 76: 83-90.

Chambers I, Colby D, Robertson M, Nichols J, et al. (2003). Functional expression cloning of Nanog, a pluripotency sustaining factor in embryonic stem cells. Cell 113: 643-655.

Coleman MA (1983). Extra 25 chicks per hen with "embryo watch". Broiler Industry 32-34.

Dai ZM, Zhu XJ and Yang WJ (2009). Full-length normalization subtractive hybridization: a novel method for generating differentially expressed cDNAs. Mol. Biotechnol. 43: 257-263.

Deb-Rinker P, Ly D, Jezierski A, Sikorska M, et al. (2005). Sequential DNA methylation of the Nanog and Oct-4 upstream regions in human NT2 cells during neuronal differentiation. J. Biol. Chem. 280: 6257-6260. 
Diatchenko L, Lau YF, Campbell AP, Chenchik A, et al. (1996). Suppression subtractive hybridization: a method for generating differentially regulated or tissue-specific cDNA probes and libraries. Proc. Natl. Acad. Sci. U. S. A. 93 : 6025-6030.

Dupuy V, Nersessian B and Bakst MR (2002). Embryonic development from first cleavage through seventy-two hours incubation in two strains of pekin duck (Anas platyrhynchos). Poult. Sci. 81: 860-868.

Etard C, Behra M, Fischer N, Hutcheson D, et al. (2007). The UCS factor Steif/Unc-45b interacts with the heat shock protein Hsp90a during myofibrillogenesis. Dev. Biol. 308: 133-143.

Etard C, Roostalu U and Strähle U (2008). Shuttling of the chaperones Unc45b and Hsp90a between the A band and the Z line of the myofibril. J. Cell Biol. 180: 1163-1175.

Eyal-Giladi H and Kochav S (1976). From cleavage to primitive streak formation: a complementary normal table and a new look at the first stages of the development of the chick. I. General morphology. Dev. Biol. 49: 321-337.

Fouse SD, Shen Y, Pellegrini M, Cole S, et al. (2008). Promoter CpG methylation contributes to ES cell gene regulation in parallel with Oct4/Nanog, PcG complex, and histone H3 K4/K27 trimethylation. Cell Stem Cell 2: 160-169.

Gupta SK and Bakst MR (1993). Turkey embryo staging from cleavage through hypoblast formation. J. Morphol. 217: 313-325.

Hart AH, Hartley L, Ibrahim M and Robb L (2004). Identification, cloning and expression analysis of the pluripotency promoting Nanog genes in mouse and human. Dev. Dyn. 230: 187-198.

Hatano SY, Tada M, Kimura H, Yamaguchi S, et al. (2005). Pluripotential competence of cells associated with Nanog activity. Mech. Dev. 122: 67-79.

Hore TA, Rapkins RW and Graves JA (2007). Construction and evolution of imprinted loci in mammals. Trends Genet. 23: 440-448.

Jérôme V, Vourc'h C, Baulieu EE and Catelli MG (1993). Cell cycle regulation of the chicken hsp90 alpha expression. Exp. Cell Res. 205: 44-51.

Ji W, Wright MB, Cai L, Flament A, et al. (2002). Efficacy of SSH PCR in isolating differentially expressed genes. BMC Genomics 3: 12.

Lande-Diner L, Zhang J, Ben-Porath I, Amariglio N, et al. (2007). Role of DNA methylation in stable gene repression. J. Biol. Chem. 282: 12194-12200.

Lavial F, Acloque H, Bertocchini F, Macleod DJ, et al. (2007). The Oct4 homologue PouV and Nanog regulate pluripotency in chicken embryonic stem cells. Development 134: 3549-3563.

Lele Z, Hartson SD, Martin CC, Whitesell L, et al. (1999). Disruption of zebrafish somite development by pharmacologic inhibition of Hsp90. Dev. Biol. 210: 56-70.

Li E, Bestor TH and Jaenisch R (1992). Targeted mutation of the DNA methyltransferase gene results in embryonic lethality. Cell 69: 915-926.

Li JY, Pu MT, Hirasawa R, Li BZ, et al. (2007). Synergistic function of DNA methyltransferases Dnmt3a and Dnmt3b in the methylation of Oct4 and Nanog. Mol. Cell Biol. 27: 8748-8759.

Lin T, Chao C, Saito S, Mazur SJ, et al. (2005). p53 induces differentiation of mouse embryonic stem cells by suppressing Nanog expression. Nat. Cell Biol. 7: 165-171.

Mezger V, Legagneux V, Babinet C, Morange M, et al. (1991). Heat shock protein synthesis in preimplantation mouse embryos and embryonal carcinoma cells. Results Probl. Cell Differ. 17: 153-166.

Miranda TB and Jones PA (2007). DNA methylation: the nuts and bolts of repression. J. Cell Physiol. 213: 384-390.

Mitsui K, Tokuzawa Y, Itoh H, Segawa K, et al. (2003). The homeoprotein Nanog is required for maintenance of pluripotency in mouse epiblast and ES cells. Cell 113: 631-642.

Neckers L (2002). Hsp90 inhibitors as novel cancer chemotherapeutic agents. Trends Mol. Med. 8: S55-S61.

Okano M, Bell DW, Haber DA and Li E (1999). DNA methyltransferases Dnmt3a and Dnmt3b are essential for de novo methylation and mammalian development. Cell 99: 247-257.

Pan G and Pei D (2005). The stem cell pluripotency factor NANOG activates transcription with two unusually potent subdomains at its C terminus. J. Biol. Chem. 280: 1401-1407.

Pearl LH, Prodromou C and Workman P (2008). The Hsp90 molecular chaperone: an open and shut case for treatment. Biochem. J. 410: 439-453.

Peng RH, Xiong AS, Xue Y, Li X, et al. (2008). Kamchatka crab duplex-specific nuclease-mediated transcriptome subtraction method for identifying long cDNAs of differentially expressed genes. Anal. Biochem. 372: 148-155.

Savli H, Aalto Y, Nagy B, Knuutila S, et al. (2002). Gene expression analysis of 1,25(OH)2D3-dependent differentiation of HL-60 cells: a cDNA array study. Br. J. Haematol. 118: 1065-1070.

Sellier N, Brillard JP, Dupuy V and Bakst MR (2006). Comparative staging of embryo development in chicken, turkey, duck, goose, guinea fowl, and japanese quail assessed from five hours after fertilization through seventy-two hours of incubation. J. Appl. Poult. Res. 15: 219-228. 
von Lindern M, Breems D, van Baal S, Adriaansen H, et al. (1992). Characterization of the translocation breakpoint sequences of two DEK-CAN fusion genes present in $\mathrm{t}(6 ; 9)$ acute myeloid leukemia and a SET-CAN fusion gene found in a case of acute undifferentiated leukemia. Genes Chromosomes Cancer 5: 227-234.

Watanabe D, Suetake I, Tada T and Tajima S (2002). Stage- and cell-specific expression of Dnmt3a and Dnmt3b during embryogenesis. Mech. Dev. 118: 187-190.

Wise-Draper TM, Allen HV, Jones EE, Habash KB, et al. (2006). Apoptosis inhibition by the human DEK oncoprotein involves interference with 53 functions. Mol. Cell Biol. 26: 7506-7519.

Wise-Draper TM, Mintz-Cole RA, Morris TA, Simpson DS, et al. (2009a). Overexpression of the cellular DEK protein promotes epithelial transformation in vitro and in vivo. Cancer Res. 69: 1792-1799.

Wise-Draper TM, Morreale RJ, Morris TA, Mintz-Cole RA, et al. (2009b). DEK proto-oncogene expression interferes with the normal epithelial differentiation program. Am. J. Pathol. 174: 71-81.

Zhulidov PA, Bogdanova EA, Shcheglov AS, Vagner LL, et al. (2004). Simple cDNA normalization using kamchatka crab duplex-specific nuclease. Nucleic Acids Res. 32: e37. 